\title{
Facilitating student nurses' learning by real time feedback of positioning to avoid pressure ulcers-Evaluation of clinical simulation
}

\author{
Lena Gunningberg , Ulrika Pöder, Cheryl Carli \\ Department of Public Health and Caring Sciences, Caring Sciences, Uppsala University, Uppsala, Sweden
}

Received: February 26, 2015

Accepted: August 16, 2015

Online Published: September 28, 2015

DOI: $10.5430 /$ jnep.v6n1p1

URL: http://dx.doi.org/10.5430/jnep.v6n1p1

\begin{abstract}
Background: Reduction of pressure and shear is recognised as the single most important intervention in order to prevent pressure ulcers (PU). Recently, an objective way to measure and receive feedback about the amount of pressure at the body-mattress interface has become available. Using such feedback in a simulated scenario in which there is a hypothetical risk for pressure ulcer development may prepare students in a safe and controlled environment for clinical placements. The aim of the study was to assess whether student nurses' learning about optimal repositioning could be facilitated by real-time feedback in a simulated PU prevention scenario.

Methods: A quantitative study was performed in the Clinical Training Center using a descriptive, comparative design. Student nurses from the second $(\mathrm{n}=24)$ and last $(\mathrm{n}=32)$ semesters worked in pairs. Their task was to place two volunteers $(69$ and 70 years) in the best pressure-reducing position (lateral and supine), initially without access to the pressure mapping monitor and then again after feedback. In total 232 positionings were conducted.

Results: Despite the controlled environment, there was considerable variation in peak-pressure readings between student pairs Mean peak pressures were consistently higher in the lateral position compared with the supine, both before and after feedback. After feedback from the pressure mapping monitor, most peak pressure readings were significantly reduced and the number of preventive interventions and patients' comfort had increased.

Conclusions: Including simulation of PU prevention in the nursing curriculum provides the possibility for students to train repositioning in a safe environment. The immediate feedback from the pressure monitoring system may strengthen students' confidence and competence on clinical placements.
\end{abstract}

Key Words: Pressure ulcer, Prevention, Pressure mapping, Student nurses, Knowledge and attitudes, Clinical simulation

\section{INTRODUCTION}

Pressure ulcers (PU) in care facilities are common, costly, distressing for the afflicted and mostly avoidable. ${ }^{[1-3]}$ Despite this, PU prevalence rates in Europe remain unacceptably high $(8.9 \%-18.1 \%),{ }^{[4-6]}$ with the prevalence rate in Sweden estimated to $14.9 \% .^{[7]}$
Fundamentally, PU prevention is a nursing responsibility. Practicing nurses and students have access to widely disseminated national and international evidence based guidelines in which PU prevention is addressed. ${ }^{[8]}$ Nurses educated in Sweden gain theoretical knowledge about PU and PU prevention during their three year undergraduate programme

\footnotetext{
*Correspondence: Lena Gunningberg; Email: Lena.gunningberg@pubcare.uu.se; Address: Department of Public Health and Caring Sciences, Uppsala, Sweden.
} 
and are expected to put theory into practice during work placements. Students are also expected to develop critical thinking skills, embrace a person centred and evidence based approach to care, realise the importance of safe practice for both patients and themselves, and understand their part in team work and the role of informatics in care. ${ }^{[9]}$ A successful integration of these expectations into the mind-sets of nurses aims to provide a solid theoretical ground on which to plan care, including PU prevention.

The results of several studies, however, reveal a fragmented understanding of $\mathrm{PU}$ prevention among registered $(\mathrm{RN})$, assistant (AN) and student nurses (SN). ${ }^{[10-12]}$ In particular, knowledge concerning the role of pressure and shear reduction was poor. This is interesting, since reduction of pressure and shear is recognised as the single most important intervention to avoid pressure ulcers. ${ }^{[8]}$ The non-blanchable erythema, which appears in the early stage of PU development, belies in many cases the extent of underlying tissue damage $^{[13]}$ and may easily be missed. Furthermore, the results of any intervention which aims to reduce pressure for the purpose of preventing a PU are not immediately forthcoming. Such an intervention may, for example, lead to an immediate increase in the patient's degree of comfort. Nursing staff can verify this by asking the patient about comfort. In contrast, the degree to which staff have succeeded in lowering pressure enough and at the right moment in order to prevent a pressure ulcer is impossible to verify. Although turning every two hours is recommended it may not prevent a PU. On the other hand, turning so often may be unnecessary and as such take time from competing nursing activities. Nurses have to allot their time wisely and the uncertainty about the correlation between intervention and outcome may partly explain the observation that nurses tend to use pressure-reducing interventions to treat rather than prevent PU. ${ }^{[14]} \mathrm{PU}$ are, with few exceptions, a late stage indicator of failed pressure reduction over time and an indication of an inadequate quality of nursing care and planning.

Most often, PU prevention in Swedish care settings is carried out by ANs while RNs have the formal responsibility for risk assessment and planning care. RNs have been observed to pay little attention to PU prevention ${ }^{[10]}$ and this may be symptomatic of a knowledge deficit or of PU prevention being assigned a lower priority by RNs as a $\mathrm{RN}$ responsibility. ${ }^{[15]}$ As such, RNs may fail to actively promote the importance of PU prevention and management and take responsibility for the outcomes. High staff turnovers in hospitals can also lead to both RNs and ANs with limited experience supervising and sharing their clinical nursing knowledge, or lack thereof, about cause and effect regarding repositioning and PU with students. Into this environment many students will come with only a priori knowledge of PU prevention, and may experience a mismatch between what is taught at university and the reality they meet in care settings. Such mismatches are unfortunate as they may hinder the retention of information by not meeting students' expectations of the importance, relevance and usefulness of pressure reducing interventions as a nursing duty.

Complementing a priori knowledge with experiential knowledge using simulation prior to clinical placements may be of benefit to students. Simulation is a learning method that offers student participation through activity and interaction ${ }^{[16]}$ and is used to model systems in order to gain insight into their functioning. Being able to see the effects of one's own attempts at repositioning patients upon levels of pressure helps to consolidate the understanding of the importance of pressure reduction. ${ }^{[12]}$

A pressure mapping system has recently been tested by RNs and ANs in one Swedish university hospital. ${ }^{[12]}$ The system allowed pressure ulcer prevention to be individualised, in contrast to routinely turning every 2 hours. Visualising the effects of repositioning lead to discussion and reasoning among the nurses about what they were actually doing and how it affected levels of pressure on the patient's body. As such, the system also provided an opportunity for peerlearning with the nurses subsequently adapting their pressure reducing routines and successfully reducing pressure in both the lateral and supine positions. The system was well accepted by the practising nurses as it provided useful information and insights about pressure reduction of relevance to their own work. It was also easy to use and understand. During the same period, student nurses with little or no previous practical experience of PU prevention also tested the mapping system using exactly the same procedure as in the aforementioned study. ${ }^{[12]}$

The aim of the study was to assess whether student nurses' learning about optimal repositioning could be facilitated by real-time feedback in a simulated PU prevention scenario. Furthermore, students' level of theoretical knowledge about PU and PU prevention as well as their attitudes to PU was investigated since these are likely to impact upon PU management.

\section{METHODS}

\subsection{Design}

A descriptive, comparative design was used in this prospective, quantitative study. Student nurses were given a validated questionnaire regarding PU knowledge and attitudes followed by observational sessions of repositioning. 


\subsection{Sample}

Student nurses were recruited from the nursing program at Uppsala University in Sweden, which is a 3-year bachelor program (6 semesters). This provided a convenience sample of 24 student nurses from the second semester (SN2) and 32 student nurses from the last semester (SN6). Mean age for the total group was 24.7 years. The majority in the sample was female and half of the students had work experience. Table 1 summarises the characteristics for the $87.5 \%(n=49)$ of participating students that completed the questionnaire.

Table 1. Student characteristics for student nurses in the second (SN2) and last semesters (SN6)

\begin{tabular}{lllll}
\hline & Total $(\mathbf{n}=\mathbf{4 9})$ & SN2 $(\mathbf{n}=\mathbf{1 8})$ & SN6 $(\mathbf{n}=\mathbf{3 1})$ & $\boldsymbol{p}$-value \\
\hline $\begin{array}{l}\text { Age-years } \\
\text { (mean (SD) range) }\end{array}$ & $24.7(2.9)$ & $23.3(2.6)$ & $25.4(2.8)$ & .014 \\
$\begin{array}{l}\text { Gender n (\%) } \\
\text { Female }\end{array}$ & $19-35$ & $19-29$ & $22-35$ & \\
$\quad$ & & & .160 \\
$\quad$ Male & $35(71.4)$ & $15(83.3)$ & $20(64.5)$ & \multicolumn{2}{|c}{0} \\
Work experience in nursing n (\%) & $14(28.6)$ & $3(16.7)$ & $11(35.5)$ & .059 \\
\hline
\end{tabular}

\subsection{Pressure mapping system}

The Continuous Bedside Pressure Mapping (CBPM) system was used to depict the distribution and amount of pressure exerted on the body at the body-mat interface. A pressure- sensing mat with thousands of sensors is placed over the patient's mattress (Optimal5zon). Readings from the sensors are converted continuously in the system's control unit into pictorial display on the unit's monitor (see Table 2). ${ }^{[17]}$

Table 2. Summary of equipment available during the observational session and outcome descriptions

\begin{tabular}{|c|c|}
\hline Pressure mapping system & $\begin{array}{l}\text { CBPM-system with preprogrammed pressure threshold at } 60 \mathrm{mmHg} \text {. Red represents pressures }>60 \mathrm{mmHg} \text {; } \\
\text { blue, green, yellow, dark orange represent increasing pressure from } 10 \text { to } 59 \mathrm{mmHg}\end{array}$ \\
\hline $\begin{array}{l}\text { Equipment for PU } \\
\text { prevention }\end{array}$ & $\begin{array}{l}\text { Bedframe: tippable; adjustable head-end; adjustable foot-ends } \\
2 \text { large pillows, } 4 \text { small pillows, } 1 \text { heel cushion, } 2 \text { wedges, } 1 \text { quilt }\end{array}$ \\
\hline Primary outcomes & $\begin{array}{l}\text { Peak interface pressure (mmHg) } \\
\text { Number of pressure-reducing changes made relative to the bed's horizontal starting position } \\
\text { "Patient" comfort assessed with a Visual Analog Scale ( } 1 \text { = Very low level of comfort; } 10 \text { = Very high level } \\
\text { of comfort) }\end{array}$ \\
\hline Secondary outcomes & $\begin{array}{l}\text { Prior to session: } \\
\text { PU Knowledge score (PUKAT) } \\
\text { PU Attitude score (APuP) } \\
\text { Immediately after session: } \\
\text { Students' experience of utility of the CBPM-system assessed with a four-point scale ( } 0 \text { = Do not agree at all; } \\
4 \text { = Agree completely). Two statements a) valuable complement to existing pressure reducing interventions, } \\
\text { b) easy to interpret data on the CBPM monitor }\end{array}$ \\
\hline
\end{tabular}

Note. CBPM: Continuous Bedside Pressure Mapping; PUKAT: PU Knowledge Assessment Tool; APuP: Attitudes towards PU.

\subsection{Data collection}

\subsubsection{Observational session}

The Clinical Training Centre, which is funded jointly by the university and the university hospital, provided two rooms for the observational session. Two volunteers, 70 years and 69 years, were recruited as single room "patients". Each room was fitted out with the same type of bed including a pressure-reducing mattress as well as equipment that is used for pressure ulcer prevention in the hospital's clinics. Table 2 provides details of the available equipment for use during the observational session as well as the study's primary and secondary outcomes. The patients were asked to abstain from helping or advising students in any way.
Student nurses worked in pairs (SN2-SN2; $\mathrm{n}=12$, SN6-SN6; $\mathrm{n}=17$ ) with both patients following a standardised procedure. They were free to position their patient in any way with the express goal to relieve pressure as best they could and using any of the available equipment, including the bed itself (see Table 2). Students were first required to place their patient on his or her side. Measures of peak pressure, patient's level of comfort, and the number of pressure-reducing interventions were recorded. The students were then allowed to view the monitor and adjust their patient's lateral position accordingly until satisfied, and repeat measurements were recorded. Using the same procedure, measurements were taken while the patient was lying on his or her back. In total, 
each student pair generated 8 sets of measurements for the two patients. Finally, student nurses assessed the utility of the CBPM system. The whole session was completed within an hour.

\subsubsection{Questionnaire}

The Swedish translated version ${ }^{[11]}$ of the PU Knowledge Assessment Tool (PUKAT) ${ }^{[18]}$ and Attitudes toward PU $(\mathrm{APuP})^{[19,20]}$ was used to assess the students' knowledge about and attitudes to PU prevention. PUKAT explores six themes through responses to 26 questions and APuP includes 13 statements assessed on a four point Likert scale (1 = strongly agree to $4=$ strongly disagree).

\subsection{Procedure}

The study was approved by the director of undergraduate nursing studies and the Ethics Review Board in Uppsala (No 2013/279). Students in second and last semesters were informed about the purpose and nature of the study during compulsory lectures, as well via e-mail and social media (Facebook). Interested students enrolled for a session through e-mail and were sent the questionnaire electronically for completion prior to the session. They were free to withdraw from the study at any time. ${ }^{[21]}$ Participation was completely voluntary and there were no academic merits given for this.

Before initiating the study, the procedure with the studyspecific protocol was reviewed several times and training in the use of the CBPM was provided until the data collectors were confident about how to use it. Data were collected during five days in February 2014. Due to attrition, six students in the last semester, were paired together with an extra student nurse, who acted as a passive partner and followed SN6's instruction when positioning the patient.

\subsection{Statistical analyses}

Comparisons between peak pressures, number of preventive interventions and levels of comfort before and after feedback were analysed using paired sample $t$-test. Independent $t$-test was used for comparison between SN2 pairs and SN6 pairs.

Knowledge scores represent the percentage of correct responses in the questionnaire. Scores for negatively worded attitudes statements were reversed, so that a higher score indicated a more positive attitude. ${ }^{[18,19]}$ The final attitude score were then calculated as a percentage of the possible total score. Independent t-test was used to compare each student group's mean knowledge and attitude score. A p-value of .05 was considered significant. SPSS 21.0 (SPSS Inc., Chicago, IL, USA) was used to analyse the data.

\section{RESULTS}

\subsection{Peak pressure, number of interventions and comfort}

Twelve SN2 pairs and 17 SN6 pairs carried out a total of 116 positionings without CBPM and a further 116 after viewing the CBPM monitor.

Initial peak pressures were higher for the male than for the female in both the lateral and supine positions regardless of student group (see Tables 3 and 4). Variation in initial peak pressures (difference between min-max peak pressures in $\mathrm{mmHg}$ ) for one and the same patient in most positions was greater within the SN2 group than the SN6 group. This was so for both patients. When SN2 positioned patients with feedback from the monitor, they produced significantly lower peak pressures in both positions for the male only (see Table 3). Both patients reported greater comfort when SN2s used feedback from the monitor to adjust the patient's positions.

Table 3. Second semester student nurse pairs $(n=12)$ : Peak pressure, number of interventions and comfort in lateral and supine position without and with feedback from the CBPM system

\begin{tabular}{|c|c|c|c|c|c|c|}
\hline \multirow{2}{*}{ Second Semester } & \multicolumn{3}{|c|}{$\begin{array}{l}\text { Male patient } \\
\text { Height } 192 \mathrm{~cm} \text {, Weight } 88 \mathrm{~kg} \text {, BMI } 23.9\end{array}$} & \multicolumn{3}{|c|}{$\begin{array}{l}\text { Female patient } \\
\text { Height } 168 \mathrm{~cm} \text {, Weight } 85 \mathrm{~kg} \text {, BMI } 30.1\end{array}$} \\
\hline & $\begin{array}{l}\text { Without } \\
\text { feedback }\end{array}$ & $\begin{array}{l}\text { With } \\
\text { feedback }\end{array}$ & $p$-value & $\begin{array}{l}\text { Without } \\
\text { feedback }\end{array}$ & With feedback & $p$-value \\
\hline \multicolumn{7}{|l|}{ Lateral left } \\
\hline Mean peak pressure, $\mathrm{mmHg}(\mathrm{SD})$ & $68.8(12.1)$ & $52.0(6.1)$ & .002 & $49.5(10.8)$ & $43.2(5.2)$ & .073 \\
\hline Min-max & $49-93$ & $42-60$ & & $33-77$ & $31-49$ & \\
\hline Number of interventions & 3.5 & 5.6 & .003 & 4.5 & 4.8 & .305 \\
\hline Mean comfort & 6.8 & 7.4 & .013 & 6.9 & 7.9 & $<.001$ \\
\hline \multicolumn{7}{|l|}{ Supine } \\
\hline Mean peak pressure, mmHg (SD) & $46.3(6.5)$ & $37.3(3.8)$ & .003 & $43.8(6.2)$ & $41.2(5.2)$ & .089 \\
\hline Min-max & $33-57$ & $30-43$ & & $33-57$ & $33-53$ & \\
\hline Number of interventions & 3.8 & 5.3 & .005 & 4.4 & 4.2 & .389 \\
\hline Mean comfort & 7.2 & 8.4 & $<.001$ & 7.4 & 8.0 & .046 \\
\hline
\end{tabular}

Note. BMI: body mass index 
Students in the last semester reduced peak pressures sig- increased their number of interventions significantly after nificantly in both positions for both patients after feedback from the monitor (see Table 4). The number of interventions they used before and after viewing the monitor, however, reviewing the monitor. Generally, the patients reported a higher degree of comfort when SN6s had used the monitor with exmained constant. In contrast, students in the second semester

Table 4. Last semester student nurse pairs $(\mathrm{n}=17)$ : Peak pressure, number of interventions and comfort in lateral and supine position without and with feedback from the CBPM system

\begin{tabular}{|c|c|c|c|c|c|c|}
\hline \multirow[t]{2}{*}{ Last Semester } & \multicolumn{3}{|c|}{$\begin{array}{l}\text { Male patient } \\
\text { Height } 192 \mathrm{~cm} \text {, Weight } 88 \mathrm{~kg} \\
\text { BMI } 23.9\end{array}$} & \multicolumn{3}{|c|}{$\begin{array}{l}\text { Female patient } \\
\text { Height } 168 \mathrm{~cm} \text {, Weight } 85 \mathrm{~kg} \\
\text { BMI } 30.1\end{array}$} \\
\hline & $\begin{array}{l}\text { Without } \\
\text { feedback }\end{array}$ & $\begin{array}{l}\text { With } \\
\text { feedback }\end{array}$ & $p$-value & $\begin{array}{l}\text { Without } \\
\text { feedback }\end{array}$ & $\begin{array}{l}\text { With } \\
\text { feedback }\end{array}$ & $p$-value \\
\hline \multicolumn{7}{|l|}{ Lateral left } \\
\hline Mean peak pressure, mmHg (SD) & $63.8(8.9)$ & $52.5(4.4)$ & $<.001$ & $47.2(4.9)$ & $43.4(3.6)$ & .003 \\
\hline Min-max & $47-83$ & $45-60$ & & $39-57$ & $35-52$ & \\
\hline Number of interventions & 5.4 & 5.4 & .791 & 4.2 & 4.1 & .727 \\
\hline Mean comfort & 6.9 & 7.5 & .002 & 7.5 & 8.6 & $<.001$ \\
\hline \multicolumn{7}{|l|}{ Supine } \\
\hline Mean peak pressure, mmHg (SD) & $50.9(5.2)$ & $41.1(4.7)$ & $<001$ & $42.9(3.6)$ & 39.8 (3.8) & 002 \\
\hline Min-max & $43-63$ & $30-49$ & $<.001$ & $37-52$ & $35-48$ & .002 \\
\hline Number of interventions & 5.0 & 5.4 & .069 & 4.7 & 5.0 & .332 \\
\hline Mean comfort & 8.1 & 8.4 & .055 & 8.5 & 9.2 & .013 \\
\hline
\end{tabular}

Note. BMI: body mass index

Comparison between the SN2 and SN6 groups showed that the SN6 group used significantly more preventive interventions for the male in both positions. The SN6 group also managed to make both patients significantly more comfortable in both positions before and after feedback compared with the SN2 group (see Table 5). However, the SN2 group produced lower peak pressures for the male in supine position compared with SN6 group from the outset and as well as after feedback.

Table 5. Differences between student nurses in second and last semester: Peak pressure, number of interventions and comfort

\begin{tabular}{|c|c|c|c|c|c|}
\hline & SN2 mean & SD & SN6 mean & SD & $p$-value \\
\hline \multicolumn{6}{|l|}{ Peak pressure } \\
\hline Male, supine without feedback & 46.3 & 6.5 & 50.9 & 5.2 & .044 \\
\hline Male, supine with feedback & 37.2 & 3.8 & 41.1 & 4.7 & .025 \\
\hline \multicolumn{6}{|l|}{ Intervention } \\
\hline Male, lateral without feedback & 3.5 & 1.4 & 5.4 & 1.5 & .001 \\
\hline Male, supine without feedback & 3.8 & 1.3 & 5.0 & 1.2 & .011 \\
\hline \multicolumn{6}{|l|}{ Comfort } \\
\hline Female, lateral without feedback & 6.9 & 0.8 & 7.5 & 0.6 & .045 \\
\hline Female, supine without feedback & 7.4 & 1.5 & 8.5 & 0.8 & .015 \\
\hline Female, supine with feedback & 8.0 & 1.5 & 9.2 & 0.9 & .009 \\
\hline Male, supine without feedback & 7.2 & 0.7 & 8.1 & 0.8 & .001 \\
\hline
\end{tabular}

SN2 and SN6 gave mean values of 3.9 and 4.0 respectively for the CBPM system as a valuable complement to existing pressure-reducing interventions. Mean values of 3.7 (SN2) and 3.8 (SN6) were given for ease of interpretation of data 
on the CBPM monitor.

\subsection{PU Knowledge and attitudes}

When both groups were taken together, students answered $55.7 \%$ of the knowledge questions correctly. Knowledge about the role of nutrition in PU development was answered correctly among $87.7 \%$ of students, however, SN2s answered this question correctly significantly more often than did SN6s $(p=.012)$. The lowest level of knowledge was seen in the theme concerning "reduction in the amount of pressure and shear", where students answered only $34.4 \%$ of those questions correctly. Ten (26.3\%) SN2s and 23 (42.4\%) SN6s demonstrated an unsatisfactory level of knowledge regarding PU (see Table 6).

Both student groups together attained an attitude score of $86.9 \%$ with no significant difference between the groups. One SN6 failed to attain the $75 \%$ threshold.

Table 6. PU knowledge and attitudes of student nurses in second (S2) and last semesters (S6)

\begin{tabular}{|c|c|c|c|c|c|c|c|}
\hline & \multicolumn{2}{|c|}{ Total $(n=49)$} & \multicolumn{2}{|c|}{ S2 $(n=18)$} & \multicolumn{2}{|c|}{ S6 $(n=31)$} & \multirow{2}{*}{$p$-value } \\
\hline & $\mathbf{M}$ & SD & $\mathbf{M}$ & SD & $\mathbf{M}$ & SD & \\
\hline \multicolumn{8}{|l|}{ Knowledge } \\
\hline Etiology and causes & 76.2 & 23.1 & 80.6 & 25.1 & 73.7 & 21.8 & .318 \\
\hline Classification and observation & 51.4 & 24.5 & 58.9 & 26.1 & 47.1 & 22.8 & .105 \\
\hline Risk assessment & 69.4 & 33.6 & 66.7 & 38.3 & 71.0 & 31.0 & .670 \\
\hline Nutrition & 87.8 & 33.1 & 100 & 0 & 80.7 & 40.2 & .012 \\
\hline Reduction in the amount of pressure and shear & 34.4 & 19.1 & 35.7 & 18.5 & 33.6 & 19.7 & .718 \\
\hline Reduction in the duration of pressure and shear & 53.1 & 20.2 & 55.6 & 18.9 & 51.6 & 21.2 & .516 \\
\hline Total score * & 55.7 & 12.9 & 59.2 & 13.1 & 53.6 & 12.5 & .145 \\
\hline $\begin{array}{l}\text { Attitude } \\
\text { Total score }^{\dagger}\end{array}$ & 86.9 & 5.3 & 86.2 & 4.4 & 87.3 & 5.8 & .480 \\
\hline
\end{tabular}

* Satisfactory knowledge score $>60 \%{ }^{[20]}$; $†$ Satisfactory attitude score $>75 \%{ }^{[20]}$

\section{Discussion}

The main finding was that, in most cases, student nurses reduced mean peak pressures significantly and their patients' experience of comfort increased after repositioning with the help of visual feedback from the CBPM monitor. For the student nurses as a group, the knowledge score was $55.7 \%$ and the attitude score was $86.9 \%$, which are similar to the results of the earlier study by Gunningberg and Carli ${ }^{[12]}$ investigating repositioning skills of RN and AN. Both studies reveal that for the same person using the same available pressurereducing equipment, peak pressure varied considerably. As seen in Tables 3 and 4, pressure levels in the lateral position for the overweight female were lower than for the male with a normal BMI. The results seem to support the observation that different body constitutions affect pressure points in a "one size fits all" bed frame. ${ }^{[22]}$

A further finding was that, RNs, ANs and SNs had similar attitude scores regarding pressure ulcer prevention. ${ }^{[12]}$ However, the average knowledge score for SN6 was $53.6 \%$ and for SN2 59.2\%. The results for SN2 are comparable with those for RNs $(60.6 \%)$ and ANs $(59.1 \%)$ in the previous study ${ }^{[12]}$ and with Swedish student nurses (6th semester) from two other universities at $61.0 \% .^{[11]}$ It is notable then, that SN6 did not attain a higher score, as this was a convenience sample and presumably the students were interested in the topic. This may indicate the importance of:

- Structuring nursing curriculums so that the pervasive risk for pressure ulcers in patients, irrespective of diagnosis or care facility, is addressed repeatedly during the three years of study, especially in regard to more complex nursing scenarios.

- Curriculums that encourage reasoning and value its application in basic nursing activities such as pressure ulcer prevention.

- Recognising additional risk factors for PU specific to certain groups, e.g., for older adults, surgical patients, premature infants, and integrating pressure ulcer prevention into the different learning modules

- Giving students the opportunity to practise pressure ulcer preventive interventions in a safe learning environment

Kitson et al. ${ }^{[23]}$ discuss the challenges nurses' face in meeting the patients' fundamental needs and in integrating physical, psychosocial and relational aspects of care into their professional modus operandi. In order to remain safe from iatrogenic harm such as hospital-acquired pressure ulcers, 
nursing education could emphasise a "thinking and linking" approach to patient care. ${ }^{[23]}$ Repositioning to prevent pressure ulcers is a nursing competency that can be fostered during undergraduate studies through linking theoretical knowledge about pressure ulcer aetiology, classification, prevention and risk assessment, with clinical observation and practical training in pressure-reducing interventions. This would leave room for students to focus on the relational aspects of PU prevention during clinical placements by drawing upon the patient's own priorities and strengths in order to achieve an individualised and, for both nurse and patient, acceptable plan for reducing the risk for PU.

Using the one-hour observational session described in this study in nursing education could facilitate "thinking and linking" and effectively help students gain insight and experience into how to relieve pressure as well as raising awareness about the variability of individuals' responses to pressure reducing interventions. A mechanistic approach to PU prevention, similar to learning how to manage an infusion pump, is not appropriate. With the help of immediate feedback from the CBPM-system students can discuss their results, reason and reflect over how and why they have positioned their faux patient as they have and how they might improve their results. ${ }^{[2]}$ Both student groups in our study reported that the CBPM system was a useful tool and easy to understand (and apparently fun). Interactive and innovative learning as a complement to deductive class room is also recommended in international PU guidelines. ${ }^{[8]}$

In this study, repositioning sessions were done by student nurses using peer-learning, but including students from other disciplines such as physiotherapy may likely have the advantage of highlighting the importance of ergonomics for both student nurses and physiotherapist students and for their future patients.

\section{Methodological considerations}

The strength of this study lies with the standardised study environment, i.e., same patients for students to reposition, the standard hospital beds and mattresses, the same available equipment for reducing pressure for both patients and the same trained data collectors during the whole study. However, tissue interface pressures do not directly measure internal tissue and capillary pressures, but is currently the best non-invasive method to measure pressures applied to the skin. Our volunteer patients consistently reported higher levels of comfort after being repositioned with feedback from the monitor and may have done so as they didn't want to discourage the students.

Even when using validated tools such as the PUKAT and $\mathrm{APuP},{ }^{[18,19]}$ there are some limitations, which should be addressed. The PUKAT was validated in Belgium and the Netherlands. Differences in practice, organisation and even language expression between Sweden and these countries may account for why students in this study found some of the questions and response alternatives difficult to comprehend. Furthermore, students' successful performance for the theme 'nutrition' may be related to the fact that it was represented by only one question. A recent psychometric study of the attitude questionnaire showed that Beeckman et al.'s fivefactor model did not fit the data well. ${ }^{[25]}$ Therefore, we used only the total attitude score in the present study.

\section{Conclusions and Relevance to Clin- ICAL PRACTICE}

Including simulation of PU prevention in the nursing curriculum provides the possibility for students to train repositioning in a safe environment. The immediate feedback from the pressure monitoring system may strengthen students' confidence and competence on clinical placements as regards PU prevention. Training repositioning on each other may also stimulate reflective peer learning through discussion, which could lead to a greater understanding and subsequently a more positive attitude to PU prevention. Starting with the students, the RNs of tomorrow and also the students' supervisors in clinical placement might break the negative loop that is previously hypothesised.

\section{ACKNOWLEDGEMENTS}

We thank the data collectors Tobias Ekstrand, David Sundström, Marcela Bravo and Henrik Pettersson. An unrestricted grant from MAP System, Wellsense Inc, Nashville, Tennessee, provided the CBPM technology at our hospital. We thank the Freemasonry for financial support.

\section{Conflicts OF InTEREST Disclosure}

The authors declare that there is no conflict of interest.

\section{REFERENCES}

[1] Baharestani MM, Black JM, Carville K, et al. Dilemmas in measuring and using pressure ulcer prevalence and incidence: an in- ternational consensus. Int Wound J. 2009; 6(2): 97-104. http: //dx.doi.org/10.1111/j.1742-481X.2009.00593.x

[2] Gorecki C, Brown JM, Nelson EA, et al. European Quality of Life 
Pressure Ulcer Project group. Impact of pressure ulcers on quality of life in older patients: a systematic review. J Am Geriatr Soc. 2009; 57: 1175-83. PMid:19486198 http://dx.doi.org/10.1111/j $.1532-5415.2009 .02307 . x$

[3] Schuurman JP, Schoonhoven L, Defloor T, et al. Economic evaluation of PU care: A cost minimization analysis of prevention strategies. Nurs Econ. 2009; 27: 390-415. PMid:20050490

[4] Barrois B, Labalette C, Rousseau P, et al. A national prevalence study of PUs in French hospital inpatients. J Wound Care. 2008; 17; 373-376, 378-379. http://dx.doi.org/10.12968/jowc. 2008. 17.9.30934

[5] Tannen A, Ekkehart D, Dassen T, et al. Explaining the national differences in pressure ulcer prevalence between the Netherlands and Germany - adjusted for personal risk factors and institutional quality indicators. J Eval Clin Pract. 2009; 15: 85-90. PMid:19239586 http://dx.doi.org/10.1111/j.1365-2753.2008.00958.x

[6] Vanderwee K, Defloor T, Beeckman D, et al. Assessing the adequacy of pressure ulcer prevention in hospitals: a nationwide prevalence survey. BMJ Qual Safe. 2011; 20: 260-267. PMid:21209147 http://dx.doi.org/10.1136/bmjqs.2010.043125

[7] Gunningberg L, Hommel A, Bååth C, et al. The first national pressure ulcer prevalence survey in county council and municipality settings in Sweden. J Eval Clin Pract. 2013; 19(5): 862-7. PMid:22640165

[8] National Pressure Ulcer Advisory Panel, European Pressure Ulcer Advisory Panel and Pan Pacific Pressure Injury Alliance. 2014. Prevention and Treatment of Pressure Ulcers: Clinical Practice Guideline. Emily Haesler (Ed.). Perth, Australia: Cambridge Media; 2014.

[9] QSEN. The Quality and Safety Education for Nurses. 2005. Available from: http: /www.qsen.org

[10] Sving E, Gunningberg L, Högman M, et al. Registered nurses' attention to and perceptions of pressure ulcer prevention in hospital settings. J Clin Nurs. 2012; 21: 1293-303. PMid:22429848 http://dx.doi.org/10.1111/j.1365-2702.2011.04000.x

[11] Gunningberg L, Mårtensson G, Mamhidir AG, et al. Pressure ulcer knowledge of registered nurses, assistant nurses and student nurses: a descriptive, comparative multicentre study in Sweden. Int Wound J. 2013; Aug 6. PMid:23919728

[12] Gunningberg L, Carli C. Reduced pressure for fewer pressure ulcers: can real-time feedback of interface pressure optimise repositioning in bed? Int Wound J. 2014. http://dx.doi.org/10.1111/iwj .12374

[13] Stekelenburg A, Gawitta D, Bader DL, et al. Deep tissue injury; how deep is our understanding? Arch Phys Med Rehabil. 2008; 89: 1410-3. PMid:18586145 http://dx.doi .org/10.1016/j .apmr . 2008.01 .012

[14] Bååth C, Idvall E, Gunningberg L, et al. Pressure-reducing interventions among persons with pressure ulcers: results from the first three national pressure ulcer prevalence surveys in Sweden. J Eval Clin Pract. 2014; 20: 58-65. PMid:23992564 http://dx.doi .org/10. $1111 /$ jep. 12079

[15] Athlin E, Idvall E, Jernfält M, et al. Factors of importance to the development of pressure ulcers in the care trajectory: perceptions of hospital and community care nurses. J Clin Nurs. 2010; 19(15-16): 2252-8. http://dx.doi.org/10.1111/j.1365-2702.2009.02886.x

[16] Bland AJ, Topping A, Wood B. A concept analysis of simulation as a learning strategy in the education of undergraduate nursing students. Nurse Educ Today. 2011; 31(7): 664-70. PMid:21056920 http://dx.doi.org/10.1016/j.nedt.2010.10.013

[17] Behrendt R, Ghaznavi AM, Mahan M, et al. Continuous bedside pressure mapping and rates of hospital-associated PUs in a medical intensive care unit. Am J Crit Care. 2014; 23: 127-33. PMid:24585161 http://dx.doi.org/10.4037/ajcc2014192

[18] Beeckman D, Vanderwee K, Demarré L, et al. Pressure ulcer prevention: development and psychometric validation of a knowledge assessment instrument. Int J Nurs Stud. 2010; 47: 399410. PMid:19781701 http://dx.doi.org/10.1016/j.ijnurst u. 2009.08.010

[19] Beeckman D, Defloor T, Demarre L, et al. Pressure ulcers: development and psychometric evaluation of the attitude towards pressure ulcer prevention instrument (APuP). Int J Nurs Stud. 2010; 47: 14321441. PMid:20466370 http://dx.doi.org/10.1016/j.ijnur stu.2010.04.004

[20] Beeckman D. Pressure ulcer prevention: Evidence-based tool development and tailored protocol implementation to improve clinical practice. [dissertation]. Ghent University; 2011.

[21] CODEX. Rules and guidelines for research: 2014 update. Available from: http://www. codex.vr.se/

[22] Moysidis T, Niebel W, Bartsch K, et al. Prevention of pressure ulcer: interaction of body characteristics and different mattresses. Int Wound J. 2011; 8: 578-584. PMid:21999615 http://dx.doi .org $/ 10.1111 / \mathrm{j} .1742-481 \mathrm{X} .2011 .00814 . \mathrm{x}$

[23] Kitson AL, Muntlin Athlin A, Conroy T. Anything but basic: Nursing's challenge in meeting patients' fundamental care needs. J Nurs Scholarsh. 2014; 46(5): 331-9. PMid:24758508 http://dx.doi.o $\mathrm{rg} / 10.1111 / \mathrm{jnu} .12081$

[24] Hatala R, Cook D, Zendejas B, et al. Feedback for simulation-based procedural skills training: a meta-analysis and critical narrative synthesis. Adv Health Sci Educ Theory Pract. 2014; (19): 251-272. PMid:23712700 http://dx.doi.org/10.1007/s10459-013-9 462-8

[25] Florin J, Bååth C, Gunningberg L, et al. Attitudes towards pressure ulcer prevention: a psychometric evaluation of the Swedish version of the APuP instrument. Int Wound J. 2014. PMid:25124833 http://dx.doi.org/10.1111/iwj.12338 